\title{
Avaliação do conhecimento dos idosos da cidade de Limeira sobre alimentos funcionais: uma análise qualiquantitativa
}

\section{Marcela M. Lage*, Rosângela M. N. Bezerra}

\section{Resumo}

Estudo descritivo, transversal em idosos voluntários residentes da cidade de Limeira através da aplicação de um questionário sociodemográfico, um roteiro de entrevista de conhecimento sobre alimentos funcionais e de um questionário de frequência alimentar. Como fator de inclusão foi selecionado para participar apenas indivíduos de 60 anos ou mais de idade, com boas condições cognitivas para compreender e responder às questões dos formulários. Os entrevistados $(n=18)$ apesar de não conhecerem a definição científica, têm familiaridade sobre os possíveis benefícios ou riscos à saúde que alguns alimentos podem oferecer. Entretanto, foi observado uma prevalência de $64 \%$ de hipertensão, $36 \%$ de diabetes e $29 \%$ de dislipidemia nos indivíduos, além de um consumo não condizente com as informações que eles detém sobre os alimentos, indicando que talvez, apenas o conhecimento não seja suficiente para uma ingestão adequada e consequentemente prevenção das doenças crônicas não transmissíveis. Há a necessidade de um consumo regular precoce dos alimentos contendo compostos bioativos aliado a bons hábitos de vida.

\section{Palavras-chave:}

Idosos, conhecimento, alimentos funcionais.

\section{Introdução}

Com o aumento da expectativa de vida é previsto que os idosos sejam mais de $20 \%$ da população em 2050 . O envelhecimento é caracterizado por mudanças morfológicas, bioquímicas, funcionais, psicológicas, entre outras, tornando os idosos mais susceptíveis a desenvolver doenças crônicas não transmissíveis (DCNT), aumentando-se a necessidade de cuidados com a alimentação e a saúde. Alguns compostos bioativos presentes nos alimentos são descritos como auxiliadores na prevenção e/ou redução do risco das DCNT, e são caracterizados como alimentos com propriedades funcionais, desde que associados a uma vida equilibrada. O objetivo do estudo foi identificar o grau de conhecimento que idosos da cidade de Limeira têm sobre alimentos funcionais.

\section{Resultados e Discussão}

Através das entrevistas foram obtidos os seguintes dados:

\section{Tabela 1. Dados Sociodemográficos}

\begin{tabular}{|c|c|}
\hline Idade & $73 \pm 8$ anos \\
\hline Feminino & $77,7 \%$ \\
\hline Masculino & $22,3 \%$ \\
\hline Casado (a) & $50 \%$ \\
\hline Ensino Superior Completo & $27,8 \%$ \\
\hline Presença de Patologias & $77,7 \%$ \\
\hline Consumo de Álcool & $33,3 \%$ \\
\hline Ex-tabagistas & $16,6 \%$ \\
\hline
\end{tabular}

Aproximadamente $66,6 \%$ dos participantes disseram ter conhecimento sobre o termo alimento funcional. Contudo, quando foi pedido para aqueles que tinham familiaridade explicassem o que era, muitos não sabiam dizer, outros responderam: "os alimentos da pirâmide alimentar", "os básicos" e "o trivial". Dos doze idosos que responderam saber o que eram alimentos funcionais, $75 \%$ acreditavam que 0 arroz e feijão fossem classificados dentro desse termo. Praticamente todos $(94,4 \%)$ disseram que alimentos trazem benefícios à saúde. As informações provinham principalmente de Família $(77,8 \%)$, Nutricionistas $(44,4 \%)$, Internet $(38,8 \%)$, Médicos $(22,2 \%)$,
Leitura (22,2\%) e Amigos (16,7\%). Alguns benefícios à saúde de alguns alimentos eram de conhecimento unânime, sendo eles: alface, rúcula, tomate, aveia, brócolis, maçã, beterraba, cenoura, alho e cebola. Outros eram também de conhecimento de todos que poderiam trazer riscos à saúde, como: salgadinho, batata frita e refrigerante; entretanto alguns alimentos causaram dúvidas, como: carne vermelha, arroz branco, sardinha, bolacha, farinha branca, chocolate e vinho. A frequência de consumo de mais de cinco vezes por semana, foi de: cebola $(100 \%)$, alho $(100 \%)$, alface $(88,9 \%)$, tomate $(72,2 \%)$, condizente com o conhecimento que eles expressaram. Já a cenoura, a maçã, a rúcula, o brócolis, a aveia e a beterraba que também foram consideradas benéficas para saúde, o consumo de mais de cinco vezes por semana foi de apenas $55,6 \%, 33,3 \%, 27,8 \%, 27,8 \%$, $16,7 \%$ e $16,7 \%$ respectivamente, valores relativamente baixos pela ciência que eles demonstraram ter sobre esses alimentos.

\section{Conclusões}

O termo Alimento Funcional ainda não é muito conhecido e divulgado entre os idosos, apesar da definição de alimentação saudável ser praticamente intrínseca a eles e o conhecimento de quais alimentos podem ser prejudiciais à saúde também. Entretanto o consumo não condiz com o que eles sabem para que sirva de fator de proteção às DCNT. Pelo fato do mundo estar envelhecendo rapidamente, é necessária a melhora dos hábitos de vida precocemente, com isso profissionais da saúde, principalmente médicos e nutricionistas podem utilizar o conceito de funcionalidade dos alimentos e ensinar a importância de uma boa alimentação como prevenção e auxílio no tratamento de algumas DCNT.

BARDIN, L. Análise de conteúdo. São Paulo: Edições 70, p.229, 2011.

CAMPOS, C. J. G. Método de análise de conteúdo: ferramenta para a análise de dados qualitativos no campo da saúde. Revista Brasileira de Enfermagem,

v.57, n.5, p.611-614, 2004.

SHIBAMOTO, T.; KANAZAWA K.; SHAHIDI, F.; HO, C. Functional Food and Health, American Chemical Society, v.993, n.1, p.1-6, 2008. 